EPJ Web of Conferences 33, 03003 (2012)

DOI: $10.1051 /$ epjconf/20123303003

(C) Owned by the authors, published by EDP Sciences, 2012

\title{
Application of liquid metals for solar energy systems
}

\author{
W. Hering, R. Stieglitz, Th. Wetzel \\ Karlsruhe Institute of Technology (KIT), 76131 Karlsruhe, Germany
}

\begin{abstract}
Liquid metals have excellent properties to be used as heat transport fluids due to the high thermal conductivity and their wide applicable temperature range. The latter opens the gate utilizing more efficient power conversion options beyond the limitations of current thermal solar energy systems. By utilizing them as thermal storage medium, an improved coupling of state-of-the art power conversion systems (PCS) to solar plants seems promising. To avoid adverse effects of highly reactive fluid a compact design is envisaged, which fits best to concentrating solar power (CSP). In this context a solar storage system is proposed and will be qualified for fast reaction to compensate solar flux fluctuations and to optimize PCS. The paper will provide an outlook based on a concept study for a 100 MWth plant with a comparison to existing thermal solar plants. The vision also includes the capability for base load applications, including a day-wide storage system. Combining both systems, a fast response of the plant to compensate short term fluctuations from other renewable sources or from energy consumption is feasible.
\end{abstract}

\section{INTRODUCTION}

The reliability and safety of energy supply is an essential pillar for economy and ecology. After the decision to phase out of nuclear energy "Energiewende" in Germany, the need for substitution of the base load capacity of nuclear energy is obvious. At a first glance wind energy is not reliable enough to provide a base load supply, bio mass is evidently limited and solar cells not efficient. Finally, thermal solar energy has good prospects as envisioned by the DESERTEC project proposal.

However, the technology challenges are very high and each technology family has to be analyzed and optimized for the planned application.

Based on KIT experiences in liquid metal technology in energy technology a proposal for a liquid metal based high temperature concentration solar power (CSP) plant is discussed. From the different technologies to concentrate solar energy only tower systems are of interest for high efficient thermal solar energy systems based on liquid metal technology. The vision will combine state-of-art power plant technology with a direct energy conversion system to be used as topping system.

\section{CHALLENGES FOR CONCENTRATING SOLAR ENERGY SYSTEMS}

The solar energy flux varies within $4-6 \mathrm{~h}$ between zero and peak power and vice versa - an awkward condition for base load power production, experiencing on a daily basis at least two major slow thermal and turbine transients. State-of the art steam turbines are optimized to a narrow load band so that each deviation from that optimal operating point yields an efficiency drop. 


\section{EPJ Web of Conferences}

Also daily occur erratic fluctuations with quite large gradients of the solar irradiation flux $\left(\mathrm{I}_{\text {sol }}\right)$ due to clouds, moisture or aerosols. In order to overcome these fluctuations with respect to the power conversion system (PCS) many solar plants/concept are designed to operate either in a solar assisted mode or in form of an "integrated solar combined cycle system" (ISCCS). However, both of those concepts are not using optimally the solar energy [1]. Hence, the challenges for concentrating solar power (CSP) can be formulated as:

1. base load capability to replace fossil and nuclear power plants,

2. long term operability to reduce costs,

3. high temperature level at turbine inlet to achieve high efficiency benefiting from fossil power plant developments,

4. thermal storage to compensate short time fluctuations and to allow base load (24/7) operation,

5. flexible power output to compensate fluctuating energy sources (wind, solar cells,...).

In order to match these goals utilizing liquid metals research on materials and thermodynamics is required with a focus on:

1.high temperature materials with low corrosion potential

2. heat transport and storage fluid with an application range up to $700^{\circ} \mathrm{C}$,

3. high temperature electromagnetic pumps (MHD),

4.long term durability of devices at fast and slow gradient erratic temperature fluctuations.

In all cases the costs of components and devices have to be taken into account. Since costs also significantly increase with the complexity of the facility, the largest potential is given by a simplified design. One simplification approach is to use only one fluid for transport and storage. Locking through the various candidates from organic, aquatic, binary, ternary alloys, liquid metals exhibit a promising high potential to fulfill these requirements. However, first practical solar implementations of liquid metals in Almeria were disappointing and ended in an accident. Based on technical progress and monitoring techniques, however, the design and the operation of liquid metal systems improved considerably so that from the CSP operational point they can be made as safe as conventional plants. Furthermore, taking advantage of the high temperatures appearing in the receiver of CSP plant, a topping cycle based on the AMTEC (Alkali Metal Thermal Electric Converter) principle can be integrated in the plant serving directly electric energy to the grid. A use of the alkali metal sodium permits the use of one liquid as transport, storage and electric conversion fluid and hence reducing the transfer processes and amount of components considerably.

In the following sections a vision of a liquid metal based CSP plant in the 100MWth class is elaborated, starting with a review of available power conversion systems, a stratified storage pool and the concept of a versatile combined solar power plant.

\section{POWER CONVERSION SYSTEMS}

At present mainly two methods to convert thermal energy into electric are commercially utilized: cycle processes using a turbine and generator such as Rankine or Brayton cycle or direct conversion systems which releases electrical energy as DC output. In the following both systems are discussed, since they are part of the proposed solar power plant.

\subsection{Conventional cycles}

State of art PCS are based on Clausius-Rankine cycle using steam/water as working fluid. With a turbine inlet temperature of approximately $600^{\circ} \mathrm{C}$, an efficiency of $50 \%$ can be attained, provided robust materials are employed. Above this temperature limit system pressure and steel corrosion increases leading to a lower reliability and higher investment costs.

From gas turbines, the Brayton cycle is known to have high efficiencies above $700^{\circ} \mathrm{C}$ as used in combined cycle power plants. In an open Brayton cycle the gas turbine use air from the environment and releases the hot flue gases through a steam boiler to a stack. For solar power plants a closed cycle is more advantageous to take credit from the higher temperature level and to use the thermal storage as heat source for prolonged daily operation. The Brayton cycle offers significantly lower system 


\section{$2^{\text {nd }}$ European Energy Conference}

pressures (7-8 $\mathrm{MPa}$, compared to steam cycle: 25-30 MPa). The working fluid can be adapted to the needs - a good candidate may be a mixture of He- $\mathrm{N}_{2}$. Nevertheless, a complete Brayton cycle is very complex operating several compressors on the turbine shaft. Designs up to $400 \mathrm{MW}_{\mathrm{e}}$ were investigated in South Africa and USA. An overview of the efficiency between $350^{\circ} \mathrm{C}$ and $950^{\circ} \mathrm{C}$ is given in Fig 1. [2].

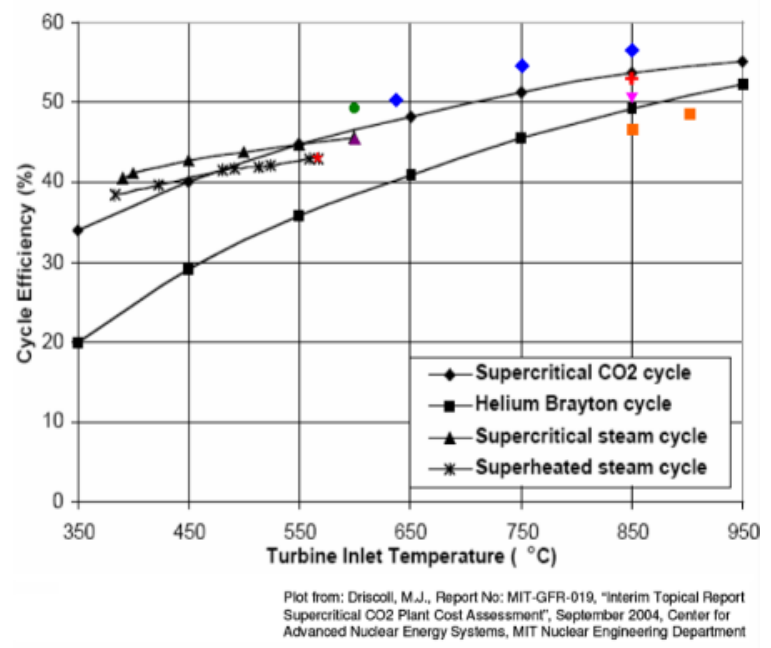

Fig. 1. Efficiencies of power conversion systems as function of the turbine inlet temperature from [2].

\subsection{Direct conversion}

\subsubsection{Overview}

The list of direct electric conversion systems is illustrated in Table 1 together with typical efficiency limitations. The physical background is a material with different heat and electrical conductivity. Heat conductivity is mainly based on lattice vibrations (phonons) while electrons or ions are responsible for electric current. Both are correlated as described by the Wiedemann-Franz law. Therefore, a good electrical conductivity indicates also good heat conductivity (metals) and vice versa (ceramics).

The Seebeck effect originates from the difference in the thermal voltage of different metals as used for thermocouples. The thermo ionic generator consists of an electrode, which thermo-ionically emits electrodes over a potential energy barrier to a colder electrode. This works only at high temperatures. In the alkali metal thermal energy converter alkali ions are used. For comparison typical efficiencies of solar cells are added in Table 1.

Table 1. Efficiencies of different direct energy converters

\begin{tabular}{|c|c|}
\hline Type & Efficiency \\
\hline Seebeck effect & $\eta<20 \%$ \\
\hline $\begin{array}{c}\text { Thermo-ionic } \\
\text { converter }\end{array}$ & $\begin{array}{c}\eta<20 \%, \\
\mathrm{~T}>1500^{\circ} \mathrm{C}\end{array}$ \\
\hline AMTEC & $20 \%<\eta<45 \%$ \\
\hline Solar cell & $\begin{array}{c}\text { Amorphous: } \sim 12 \% \\
\text { Crystalline: } \sim 20 \% \\
\text { Tandem: } \sim 31 \%\end{array}$ \\
\hline
\end{tabular}




\subsubsection{AMTEC}

The alkali metal thermal electric converter (AMTEC) is not a new technology, it was invented by Researchers at Ford Scientific Laboratories, in Dearborn, USA, in 1968 when they identified and patented a converter known as the sodium heat engine. AMTEC was investigated at KfK (precursor of the Karlsruhe Institute for Technology-KIT) until 1995 (see Fig 3) as a spin-off from the sodium technology [3, 4]. Several issues were investigated and test devices were built. The technological challenges were identified and possible solutions presented. Progress in high temperature material technology now allows to reinvestigate AMTEC as an efficient energy source to be used as a topping system for solar and fusion (divertor output) energy systems.

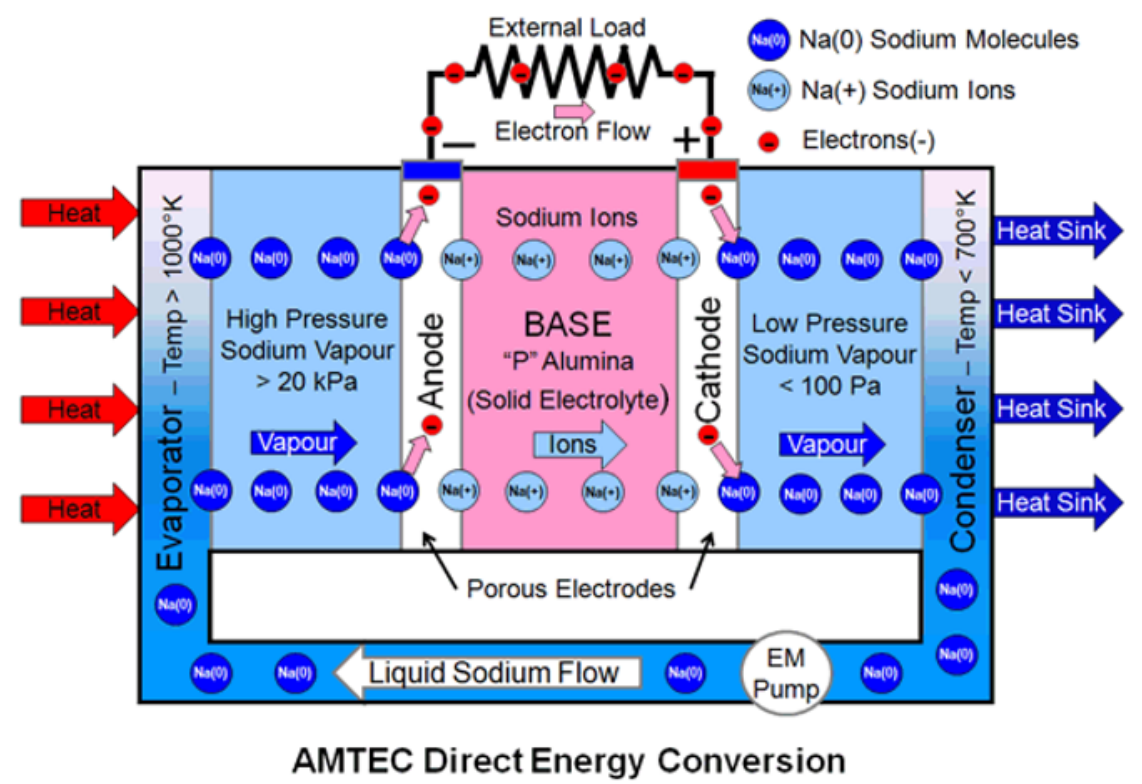

Fig. 2. Schematics of the functional principle of an AMTEC cell.

AMTEC is a thermally regenerative electro-chemical device for direct conversion of heat into electricity. AMTEC has high efficiency relative to other direct electric converters. Liquid sodium is pumped by an electro-magnetic pump (MHD pump) from the condenser (right side in Fig. 2) to the evaporator, where it is converted to vapor due to heat from some external source (combustion, solar, nuclear,...). The sodium dissociates at the central element of AMTEC, the "beta alumina solid electrolyte" (BASE, $\mathrm{Na}_{2} \mathrm{O}-\mathrm{Al}_{2} \mathrm{O}_{3}$ ) surface, since only Na-ions can travel through the BASE. The electrons circulate through the external load producing electrical work and reach the cathode surface where they recombine with the sodium ions at the interface between the BASE and cathode.

The BASE divides the AMTEC into two regions; a hot region filled with sodium at high-pressures $(20-100 \mathrm{kPa})$ and high-temperatures $(900-1300 \mathrm{~K})$ and a cold region at low-pressures $(<100 \mathrm{~Pa})$ and low-temperatures (400-700 K). AMTEC does not have any moving parts except for the transported sodium, which flows in a closed cycle as a working fluid. Electrodes on both sides supply power to an external load. Several cells are connected in series to increase the voltage. Presently, typical current densities are $0.5 \mathrm{~A} / \mathrm{cm}^{2}$.

The driving force is the thermodynamic potential difference and hence the pressure difference between hot and cold side. The theoretical efficiency of AMTEC is close to Carnot limit; however, due to technical limitations at present efficiencies of approximately $30 \%$ have been obtained [5, 6]. Due to the high temperature level, the excess energy can be used for the conventional power conversion systems (PCS) or stored in a high temperature storage device. 


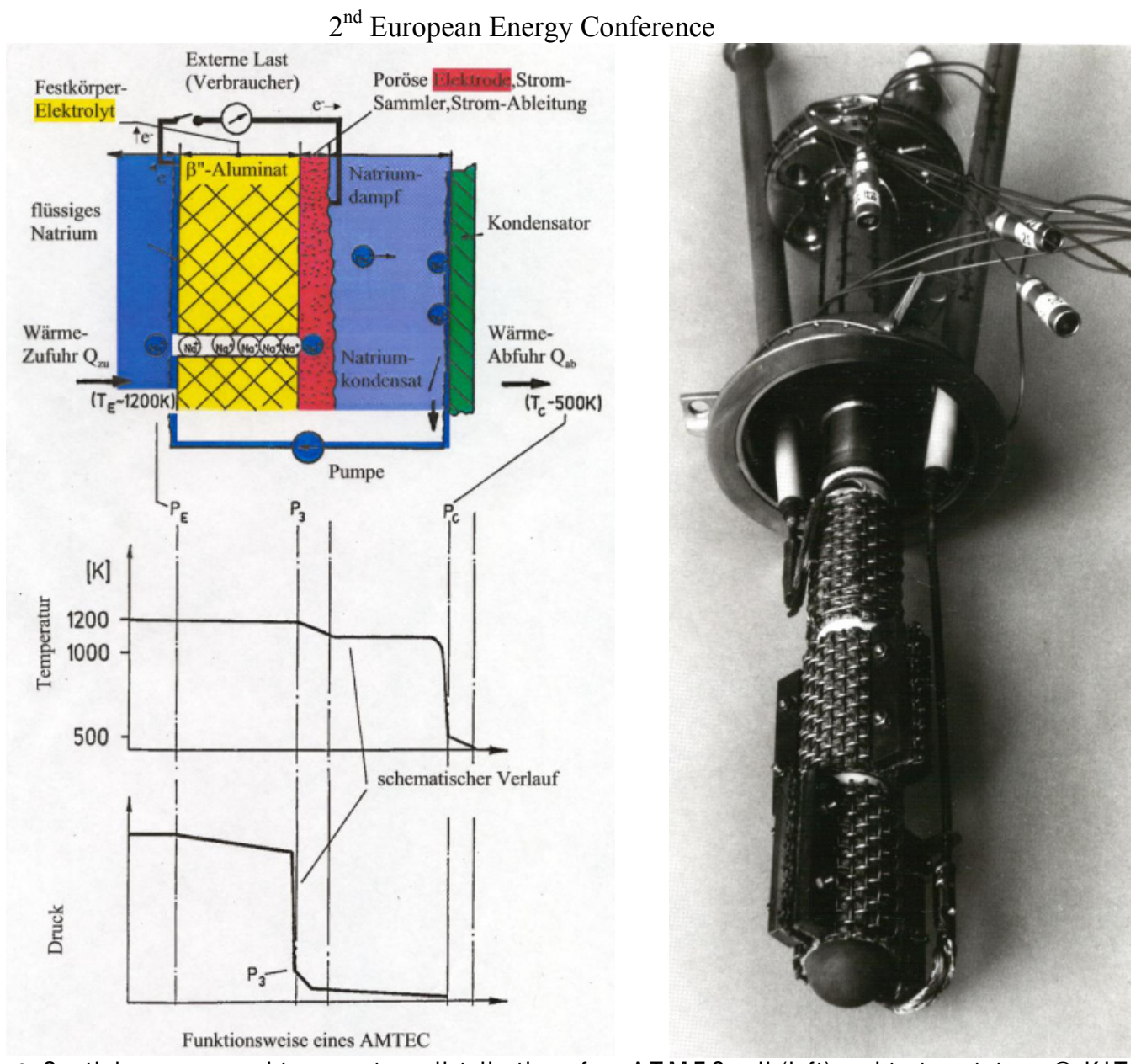

Fig. 3. Spatial pressure and temperature distribution of an ATMEC cell (left) and test prototype @ KIT (right).

\section{STORAGE DEVICE}

Traditionally thermal solar plant uses a two tank storage system. The storage fluid is pumped via a heat exchanger between both tanks, one full the other empty. For higher temperatures such a schematic is not optimal, since twice the insulation is needed.

Aside from air ingress due a potential leak in an empty container and its consequences a single thermocline avoids such a scenario. Taking advantage of this option not only minimizes the amount of piping, control and components, moreover, by this measure also thermal transients in the container wall material are reduced. Such a stratified thermal is presently under development in the KASOLA facility at KIT [8]. A thermocline type arrangement allows keeping the liquid volume constant and the thermal expansion is compensated in a special expansion tank at a lower temperature utilizing conventional material as denoted in Fig. 4.

In this concept a floating disk separates hot zone located at the top from the cold one in the storage tank. To reduce thermal losses through the disk it is filled by a radiation isolation and Argon. The floatation is stable if a minimum temperature difference is maintained. Presently, analyses to optimize the disk and the storage tank for different plant sizes are under way.

A rough estimation of size required for a $100 \mathrm{MW}_{\text {th }}$ plant leads to the following values. For base load capability a $24 \mathrm{~h}$ operation has to be ensured. Assuming a minimal solar thermal collection acceptance time for the storage of 8 hours, the storage system device must be dimensioned to bridge $16 \mathrm{~h}$, which translates to a thermal energy to be stored of $1.610^{6} \mathrm{kWh}$. Using sodium as transport and 
storage fluid with a heat capacity of $\sim 0.28 \mathrm{kWh} /\left(\mathrm{m}^{3} \mathrm{~K}\right)$ and a temperature span from $200^{\circ} \mathrm{C}$ to $550^{\circ} \mathrm{C} \mathrm{a}$ volume of $16.500 \mathrm{~m}^{3}$ is required. This in turn corresponds to a tank with a height of $40 \mathrm{~m}$ and a diameter of $22 \mathrm{~m}$, which is considerably smaller than two separate tanks. Such a compact design allows an integration of the entire sodium inventory inside the solar tower, which drastically reduces the safety evaluation necessary for sodium operation, since from industrial and nuclear applications well defined tools and measures for a safe operation are available.

\section{COMBINED CYCLE}

The integration of AMTEC and the storage concept in a solar thermal system yields an innovative solar plant design, which is sketched in principle in Fig. 4. The direct conversion AMTEC operates as a topping system in the temperature range from $900^{\circ} \mathrm{C}$ (receiver) to $550^{\circ} \mathrm{C}$. The relatively "cold" sodium at a temperature level of $500-600^{\circ} \mathrm{C}$ is transported to the storage tank and replaced by cold sodium at about $200^{\circ} \mathrm{C}$. This provides a high efficiency of the AMTEC and also thermal energy for the conventional power conversion system. The output of the AMTEC is converted to AC and connected to the grid. After ceasing of solar flux, AMTEC is shut down. The power conversion system continues working now supplied by heat from the storage tank. Alternatively and to enhance flexibility, a sodium cooled receiver can be used in parallel as illustrated in Fig 4.

The PCS and the circulation pump can operate at steady state and only valves control the energy transfer in or out of the storage container. Consequently, the motion of the interface disk is a measure of energy stored in the system. The combine cycle named A\&CP (AMTEC \& Conventional PCS) shows similar advantages compared to gas turbine \& steam cycle while reducing the daily thermal stresses to the AMTEC section solely.

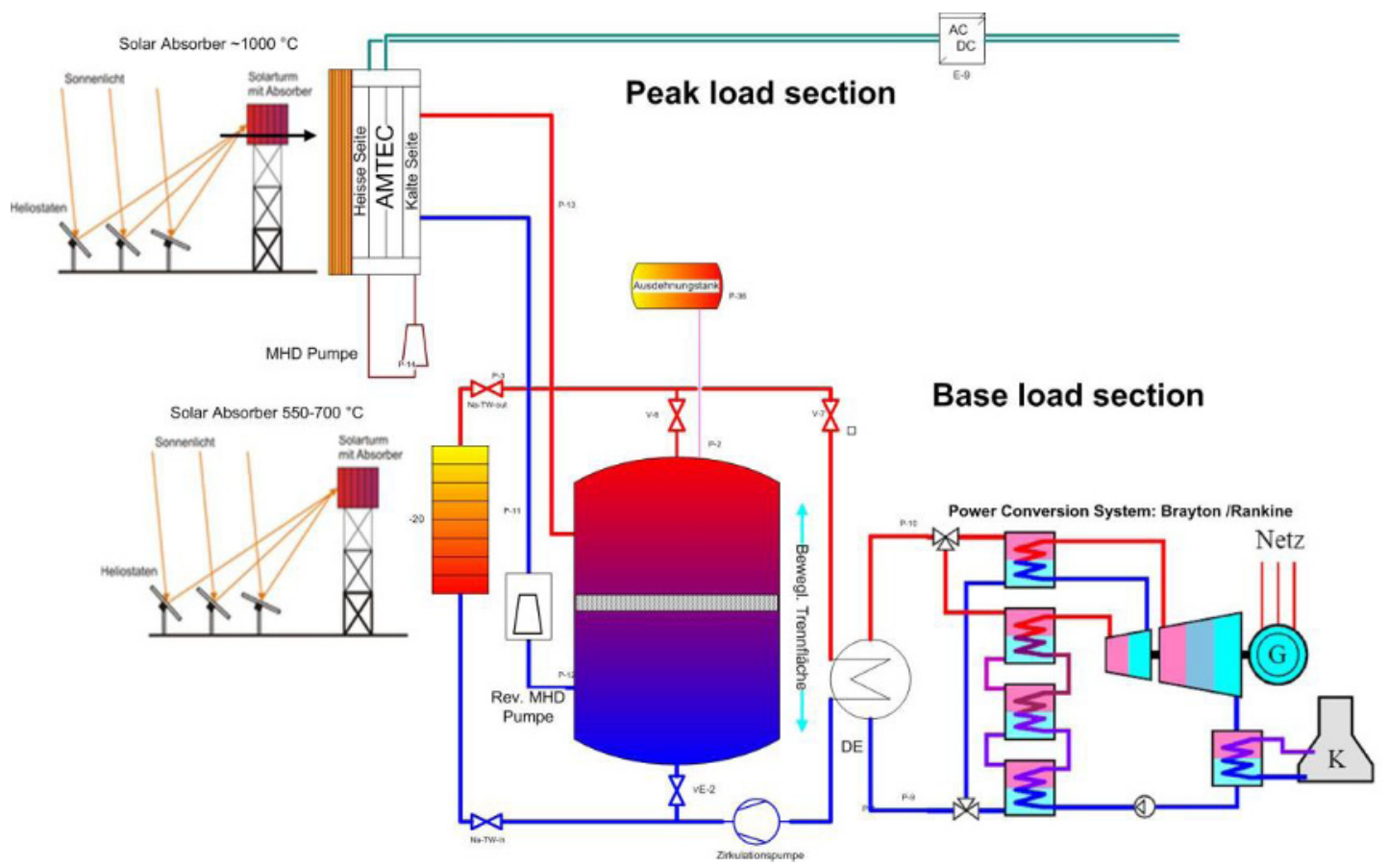

Fig. 4. Concept of an innovative combined A\& CP solar thermal plant [7].

The major advantage of the A\&CP is, that the combined efficiency of AMTEC and state-of-art PCS allows the best utilization of the stored energy. Thermal solar energy systems will be operated primarily in desert areas where the daily peak temperature reaches more than $40^{\circ} \mathrm{C}$ while during night temperatures drop to a few degrees centigrade. The low temperatures during night increase the temperature difference leading to better conditions in the condenser. Furthermore, the presented 


\section{$2^{\text {nd }}$ European Energy Conference}

technology can profit from the research on material sciences as well as nuclear technology and safety [6].

Measured AMTEC efficiencies and state of the art PCS values allows an estimated overall efficiency of about $30 \%$ for an A\&CP power plant compared to a value of $15-20 \%$ of current systems. At present, however, the capital investments for an A\&CP are somewhat larger and still necessitate R\&D efforts, but they may be compensated by a longer and more flexible operation. Due to the thermal storage, such CSP can be used as carbon free energy source to balance the fluctuating renewable energy sources in a second step.

\section{Summary and outlook}

For CSP liquid metal systems are proposed together with a topping cycle using an AMTEC device. Since AMTEC uses sodium as working fluid, sodium is considered both as heat transport and storage fluid. The concept of a $100 \mathrm{MW}_{\text {th }}$ power plant includes a large thermal storage to protect the power conversion system from daily thermal transients and hence to increase life time considerably. An additional flexibility is provided by the topping system, which extends the applicable temperature range to those delivered by solar tower systems. To realize such a concept several multi-disciplinary research is necessary and initiated sponsored by the German government.

\section{References}

1. Baghernejad, A. , Yaghoubi, M., Exergoeconomic analysis and optimization of an Integrated Solar Combined Cycle System (ISCCS) using genetic algorithm. (2011), Energy Conversion and Management, 52(5), p. 2193-2203.

2. Driscoll M.J., Supercritical $\mathrm{CO}_{2}$ Plant Cost Assessment, (2004), Report No: MIT-GFR-019, Interim Topical Report, Center for Advanced Nuclear Energy Systems, MIT Nuclear Engineering Department.

3. Steinbrueck, M.; Heinzel, V.; Huber, F.; Peppler, W.; Will, H.; Voss, M. Investigations of betaalumina solid electrolyte for application in AMTEC cells, (1993), Proc. of the $28^{\text {th }}$ Intersociety Energy Conversion Engineering Conf. (IECEC-93), Atlanta, Ga., August 8-13, 1993 Vol. 1 Washington, DC : American Chemical Society (1993), p.1799-1807.

4. Heinzel, V.; Huber, F.; Peppler, W.; Steinbrueck, M.; Voss, M.; Will, H. AMTEC-Zellen. Ergebnisse des Kernforschungszentrums Karlsruhe. Sonnenenergie 2 (1993) pp. 14-16.

5. M.A.K. Lodhi, A. Daloglu, Performance parameters of material studies for AMTEC cell, (2000), J. Power Sources, 85, p. 203-211.

6. Shuang-Ying $\mathrm{Wu}, \mathrm{A}$ review on advances in alkali metal thermal to electric converters (AMTEC), (2009), Int. J. Energy Res. 33, p.868-892.

7. W. Hering, R. Stieglitz, Qualification requirements for innovative instrumentation in advanced nuclear systems, PAMIR-8, International Conference on Fundamental and Applied MHD, 5.-909.2011.

8. Hering, W., Stieglitz R., Wetzel, Th. Flüssigmetalle für solarthermische Anwendungen Jahrestreffen der DECHEMA Fachgruppen Energieverfahrenstechnik \&Hochtemperaturtechnik, ProcessNet 2012, 7.-9.03.2012, Frankfurt.

9. Denholm P., King J.C., Kutcher C.F., Wilson P.H., Decarbonizing the electric sector: Combining renewable and nuclear energy using thermal storage, (2012), Energy Policy 44, p. $301-311$. 